\title{
Evaluasi Ruang Terbuka Hijau di Kota Pekanbaru
}

\author{
DOI 10.18196/pt.2015.038.41-51
}

\author{
Lis Noer Aini*, Bambang Heri Isnawan, Endri Ridwan Saleh \\ Program Studi Agroteknologi, Fakultas Pertanian, Universitas Muhammadiyah Yogyakarta, \\ Jl. Lingkar Selatan, Kasihan, Bantul, Yogyakarta 55183, Indonesia Telp. 0274387656 , \\ *Corresponding author: nenny@umy.ac.id
}

\begin{abstract}
ABSTRAK
Penelitian tentang evaluasi ruang terbuka hijau di kota Pekanbaru bertujuan untuk mengevaluasi ketersediaan (lokasi, luas dan jenis), bentuk Ruang Terbuka Hijau (RTH) Kota Pekanbaru dan membuat model penataan Ruang Terbuka Hijau (RTH). Evaluasi dilakukan untuk meningkatkan nilai fungsional dan estetika dari ruang terbuka hijau. Area yang dipilih sebagai bahan kajian adalah jalur hijau jalan di jalan utama, taman kota dan hutan kota yang ada di Kota Pekanbaru. Penelitian dilaksanakan dengan menggunakan metode survey melalui observasi, serta pengumpulan data primer dan sekunder. Pemilihan lokasi dilakukan dengan metode purposive sedangkan pemilihan responden menggunakan accidental sampling dengan jumlah responden 72 orang. Data yang telah diperoleh dianalisis dengan menggunkana metode deskriptif dan spasial dilanjutkan dengan penataan ruang terbuka hijau untuk meningkatkan fungsi dan nilai estetika. Hasil penelitian menunjukan bahwa kota Pekanbaru hanya memiliki 4,35\% ruang terbuka hijau publik dalam bentuk kawasan lindung (jalur hijau, taman kota, hutan kota), kuburan dan danau wisata. Kota Pekanbaru belum memiliki luas RTH publik sesuai UU Nomor 26 tahun 2007 minimal $20 \%$ dari luas wilayah dan RTRW Kota Pekanbaru minimal 49\% dari luas wilayah. Model perencanaan jalur hijau jalan di Jl. Sukarno Hatta, Jl. Riau, Jl. Hang Tuah, Jl. Imam Munandar Jl. Subrantas, dan Jl. Tuanku Tambusai didasarkan pada kebutuhan jalan pada tanaman peneduh, penahan angin dan penyerap polusi. Model perencanaan hutan kota yang direncanakan adalah hutan kota rekreasi dengan penggabungan tanaman dan perkerasan. Model perencanaan taman persimpangan Jl. Subrantas didasarkan pada kebutuhan tanaman peneduh dan ruang untuk interaksi para pengguna pasar.

Kata kunci: Ruang terbuka hijau, Kota pekanbaru, Evaluasi area
\end{abstract}

\begin{abstract}
The research was conducted to evaluate the availability of open green area in Pekanbaru and to make the landscape model of green open area. This evaluation was needed to improve the functional and aesthetic value of green open area in Pakanbaru. The green areas were the main street of ring road, city park and forest. The research was carried out by using implementation methods of technical survey by observation, collective secondary and primary data. Election area was elected by purposive way and respondent method election done non-probability sampling technique that taking sample research by non-random way by 72 numbers of respondent. Data was analyzed by descriptive and spacial method, so continued by structuring of green open space to improve of develop functional value and aesthetic value in Pekanbaru. The research showed that the Pekanbaru City has 4,35\% of green space in the shape of protecting areas, lake tours, and the grave till Pekanbaru City does not have wide green open space public as mandated by law no 26 year 2007 at least 20\% from the areas spatial planning Pekanbaru, namely 49\% of the area of Pekanbaru City. Planning model green lane road on Jl. Sukarno Hatta, J1. Subrantas, Jl. Riau, Jl. Hang Tuah, Il. Imam Munandar and Jl. Tuanku Tambusai based on the needs of the road to plant shade, windbreak and absorbing pollution. Planning Model urban forest planning was urban forest recreation by combining soft elements and hard elements. Planning model park junction 11. Subrantas based on plant shade needs and space for the interaction for market users.

Keywords: Green area, Pekanbaru City, Land evaluation
\end{abstract}

\section{PENDAHULUAN}

Perkembangan kota sering menggeser keberadaan ruang publik, sehingga kuantitas dan kualitas ruang terbuka khususnya Ruang Terbuka Hijau (RTH) saat ini mengalami penurunan yang sangat signifikan dan mengakibatkan penurunan kualitas lingkungan hidup perkotaan yang berdampak ke berbagai sendi kehidupan perkotaan antara lain sering terjadinya banjir, peningkatan pencemaran udara, dan menurunnya produktivitas masyarakat akibat terbatasnya ruang yang tersedia untuk interaksi sosial (Peraturan Menteri Pekerjaan Umum, 2010).

Secara sistem, RTH kota berfungsi menunjang keamanan, kesejahteraan, peningkatan kualitas lingkungan dan pelestarian alam. RTH kota pada umumnya terdiri dari ruang pergerakan linear atau koridor dan ruang pulau atau oasis (Hakim dan Utomo, 2002 cit. Nugroho, 2006). Menurut Bernatzky, 1978 cit. Nugroho (2006) suatu wilayah yang tidak memiliki RTH 
dapat menimbulkan ketidaknyamanan bagi manusia yang tinggal di dalamnya.

Pesatnya perkembangan Kota Pekanbaru berpotensi menggeser keberadaan RTH di Kota Pekanbaru. Dalam evaluasi rencana umum tata ruang (RUTR) Kota Pekanbaru tahun 1991, arahan kawasan non terbangun khususnya yang berfungsi sebagai kawasan lindung pada tahun 2015 diidentitifikasikan dalam RUTR Kota Pekanbaru seluas 16.768 Ha. Kenyataannya pada tahun 2006 kawasan lindung baru mencapai 2.487,65 Ha. Dalam perjalanan pengembangan kawasan lindung Kota Pekanbaru hingga tahun 2015 telah terjadi alih fungsi lahan peruntukan kawasan lindung menjadi kawasan terbangun seperti pemukiman, perdagangan, industri, perkebunan, dan semak belukar. Bergesernya keberadaan RTH di Kota Pekanbaru dapat menjadikan Kota Pekanbaru menjadi tidak nyaman, salah satunya ditunjukkan oleh tingginya suhu di Kota Pekanbaru mencapai $34^{\circ} \mathrm{C}-35^{\circ} \mathrm{C}$ (Media Indonesia, 2010).

Salah satu fungsi RTH yaitu sebagai pengendali iklim mikro, sarana menciptakan kesehatan, dan kehidupan lingkungan hidup. RTH juga berfungsi secara ekologis, menjamin keberlanjutan suatu wilayah kota secara fisik, dan merupakan satu bentuk RTH yang berlokasi, berukuran, dan berbentuk pasti dalam suatu wilayah kota, seperti RTH untuk perlindungan sumberdaya penyangga kehidupan manusia dan untuk membangun jejaring habitat kehidupan liar. RTH untuk fungsi-fungsi lainnya (sosial, ekonomi, arsitektural) merupakan RTH pendukung dan penambah nilai kualitas lingkungan dan budaya kota tersebut, sehingga dapat berlokasi dan berbentuk sesuai dengan kebutuhan dan kepentingannya, seperti untuk keindahan, rekreasi, dan pendukung arsitektur kota (Nugroho, 2006).

Undang-Undang (UU) Nomor 26 Tahun
2007 tentang Penataan Ruang memberikan landasan untuk pengaturan ruang terbuka hijau dalam rangka mewujudkan ruang kawasan perkotaan yang aman, nyaman, produktif, dan berkelanjutan (UU Republik Indonesia Nomor 26 tahun 2007). Tujuan penelitian ini adalah mengevaluasi ketersediaan (lokasi, luas dan jenis) dan bentuk Ruang Terbuka Hijau (RTH) Kota Pekanbaru dan membuat model penataan Ruang Terbuka Hijau (RTH) untuk meningkatkan nilai fungsional dan estetika.

\section{BAHAN DAN METODE}

Penelitian telah dilaksanakan di Kota Pekanbaru. dengan menggunakan metode survey. Teknis pelaksanaannya dilakukan dengan observasi, pengumpulan data sekunder dan primer. Beberapa hal yang harus diperhatikan dalam observasi ini adalah identifikasi pemanfaatan lahan, fungsi, jalan serta kondisi sosial. Pemilihan lokasi observasi dengan cara purposive yaitu pengambilan sampel yang secara sengaja dipilih berdasarkan tujuan penelitian. Dalam penelitian ini dipilih Kota Pekanbaru, karena dalam evaluasi rencana umum tata ruang (RUTR) Kota Pekanbaru tahun 1991, arahan kawasan non terbangun khususnya yang berfungsi sebagai kawasan lindung pada tahun 2015 direncanakan seluas $16.768 \mathrm{Ha}$. Pada kenyataannya tahun 2006 kawasan lindung baru mencapai 2.487,65 Ha. Dalam perjalannan pengembangan kawasan lindung Kota Pekanbaru hingga tahun 2015 telah terjadi alih fungsi lahan peruntukan kawasan lindung menjadi kawasan terbangun seperti pemukiman, perdagangan, industri, perkebunan, dan semak belukar.

Metode pemilihan responden dilakukan dengan teknik non-probability sampling yaitu pengambilan sampel penelitian secara non-random (tidak acak) (Supardi. 2005). Responden dipilih dengan cara accidental sampling atau sering 
disebut dengan convenience sampling. Responden yang dipilih adalah masyarakat Kota Pekanbaru sebagai pengguna RTH. Saat pelaksanaan tidak semua responden bersedia mengisi kuisioner sehingga total responden yang dapat dijadikan sampel berjumlah 72 orang.

Data-data yang terkumpul dianalisis dengan metode deskriptif dan spasial. Analisis deskriptif digunakan untuk memberikan gambaran, penjelasan dan uraian hubungan antara satu faktor dengan faktor lain berdasarkan fakta, data dan informasi kemudian dibuat dalam bentuk tabel atau gambar. Analisis spasial digunakan untuk menentukan pola ruang dan dilanjutkan membuat model penataan RTH untuk meningkatkan nilai fungsional dan estetika di kota Pekanbaru.

Tabel 1. Jenis Data dan Sember yang Digunakan dalam Penelitian

\begin{tabular}{|c|c|c|c|c|}
\hline No. & Jenis Data & Lingkup & Bentuk Data & Sumber \\
\hline 1. & $\begin{array}{l}\text { Rencana tata ruang } \\
\text { dan wilayah }\end{array}$ & & Hard copy & BAPPEDA \\
\hline 2. & Geografis wilayah & $\begin{array}{l}\text { Batas wilayah dan luas } \\
\text { wilayah }\end{array}$ & Hard copy & BAPPEDA \\
\hline 3. & Iklim & $\begin{array}{l}\text { Ketinggian tempat, curah } \\
\text { hujan, suhu, dan kelemba- } \\
\text { ban relative }\end{array}$ & Hard copy & BPS \\
\hline 4. & Kondisi sosial & $\begin{array}{l}\text { Jumlah penduduk, pendi- } \\
\text { dikan, tingkat ekonomi, } \\
\text { kepadatan penduduk, dan } \\
\text { pekerjaan }\end{array}$ & Hard copy & BPS \\
\hline 5. & Inventaris RTH & $\begin{array}{l}\text { Jumlah tanaman tepi jalan, } \\
\text { taman kota dan hutan kota } \\
\text { serta sejenisnya }\end{array}$ & Hard copy & $\begin{array}{c}\text { Dinas } \\
\text { Pertamanan }\end{array}$ \\
\hline 6. & Persepsi masyarakat & Kuisioner & Kuisioner & $\begin{array}{c}\text { Masyarakat } \\
\text { Pekanbaru }\end{array}$ \\
\hline
\end{tabular}

Kota Pekanbaru terletak antara $101^{\circ} 14^{\prime}$ 101³4' Bujur Timur dan 0²5' - 045' Lintang Utara. Dengan ketinggian dari permukaan laut berkisar 5 - 50 meter. Permukaan wilayah bagian utara landai dan bergelombang dengan ketinggian berkisar antara 5-11 meter. Perda Kota Pekanbaru No. 4 Tahun 2003 menjadikan Kota Pekanbaru terbagi atas 12 Kecamatan dan $58 \mathrm{Ke}$ lurahan/Desa dengan luas wilayah 632,26 km².
Kota Pekanbaru keadaannya relatif daerah datar dengan struktur tanah pada umumnya terdiri dari jenis alluvial dengan pasir. Pinggiran kota umumnya terdiri dari jenis tanah organosol dan humus yang merupakan rawa-rawa bersifat asam, sangat korosif untuk besi.

Kota Pekanbaru pada umumnya beriklim tropis dengan suhu udara maksimum berkisar antara $34,1^{\circ} \mathrm{C}-35,6^{\circ} \mathrm{C}$ dan suhu minimum antara $20,2^{\circ} \mathrm{C}-23,0^{\circ} \mathrm{C}$. Curah hujan antara 38,6 - 43,50 mm/tahun dengan keadaan musim berkisar : Musim hujan jatuh pada bulan Januari s/d April dan September s/d Desember. Musim Kemarau jatuh pada bulan Mei s/d Agustus. Kelembaban maksimum antara 96\% - 100\%. Kelembapan minimum antara 46\% - 62\%.

\section{HASIL DAN PEMBAHASAN}

Kondisi Eksisiting Ruang Terbuka Hijau (RTH) Kota Pekanbaru

Secara khusus kondisi eksisting RTH Kota Pekanbaru terbagi atas tanaman tepi jalan, hutan kota, dan taman kota. RTH yang ada di Kota Pekanbaru tersebar di 12 kecamatan yakni Tampan, Payung Sekaki, Bukit Raya, Marpoya Damai, Tenayan Raya, Lima Puluh, Sail, Pekanbaru Kota, Sukajadi, Senapelan, Rumbai Pesisir dengan kuantitas dan kualitas yang berbeda-beda.

\section{Jalur Hijau Jalan di Kota Pekanbaru}

Objek pengamatan jalur hijau jalan di Kota Pekanbaru dilakukan pada jalan utama, yaitu Jl. Jendral Sudirman, Jl. Hang Tuah, Jl. H. Imam Munandar, Jl. Sukarno Hatta, Jl. Subrantas, Jl. Tuanku Tambusai, Jl. Arifin Ahmad dan Jl. Riau. Kondisi eksisting jalur hijau jalan pada jalan-jalan tersebut berbeda-beda, ada beberapa jalan yang memiliki ketersediaan tanaman tepi jalan yang cukup dan penataannya sudah baik, namun ada juga dari beberapa jalan masih memi- 
liki ketersediaan tanaman tepi jalan yang sedikit dan penataannya masih kurang baik

Kondisi jalur hijau jalan di Jl. Sukarno Hatta bagian timur masih kurang tertata. Keberadaan tanaman tepi jalan di ruas jalan tersebut belum mampu menahan kencangnya angin yang ada dan menurunkan suhu yang terasa sangat panas. Kondisi ini sangat berbeda dengan Jl. Sukarno Hatta bagian barat, jalur hijau telah tertata dan sudah ditanami berbagai macam tanaman peneduh serta tanaman penutup tanah antara lain Dadap Merah, Angsana, Biola Cantik, dan Bintaro.

Kondisi jalur hijau jalan di Jl. Subrantas masih kurang tertata. Keberadaan tanaman tepi jalan di ruas jalan tersebut belum mampu menahan kencangnya angin yang ada dan menurunkan suhu saat terik matahari.

Kondisi jalur hijau jalan di Jl. Arifin Ahmad telah tertata. Keberadaan tanaman tepi jalan di ruas jalan tersebut mampu menciptakan suasana sejuk dan nyaman.

Jalur hijau jalan di Jl. Imam Munandar kurang tertata. Pada jalur tanaman hampir seluruhnya perkerasan. Terdapat beberapa tanaman peneduh seperti Mahoni dan Angsana, namun jumlahnya relatif masih sedikit. Pada siang hari, ruas jalan ini terjadi fatamorgana karena teriknya matahari pada siang hari.

Jalur hijau jalan di Jl. Jendral Sudirman termasuk kategori yang terbaik diantara seluruh ruas jalan di Kota Pekanbaru. Jalur hijau jalan telah tertata dan keberadaan tanaman tepi jalan di ruas jalan ini mampu menciptakan kenyamanan bagi pengguna jalan.

Kondisi jalur hijau jalan di Jl. Hangtuah hampir sama dengan kondisi jalur hijau jalan di Jl. Imam Munandar. Jalur tanaman sebagian besar dipenuhi perkerasan dengan beberapa tanaman peneduh seperti Glodokan, Mahoni, Angsana,
Akasia dan Tanjung. Keberadaan tanaman tepi jalan pada jalan tersebut belum mampu menurunkan panasnya suhu udara saat terik matahari.

Kondisi jalur hijau jalan di Jl. Riau sangat mirip dengan kondisi jalur hijau di Jl. Imam Munandar dan Jl. Hangtuah. Pada ruas jalan sedikit dijumpai tanaman tepi jalan. Jenis tanaman yang dijumpai di ruas jalan ini berupa tanaman peneduh seperti Mahoni dan Angsana. Keberadaan tanaman tepi jalan pada Jl. Riau juga belum mampu menurunkan panasnya suhu udara di siang hari.

Jalur hijau jalan di Jl. Tuanku Tambusai masih kurang tertata. Keberadaan tanaman tepi jalan pada jalan tersebut belum mampu menurunkan panasnya terik matahari di siang hari. Jalur tanaman telah ditanami tanaman peneduh seperti Mahoni, namun dalam jumlah relatif sedikit. Jalur tanaman pada jalan ini mirip dengan Jl. Subrantas yang dipenuhi dengan perkerasan.

\section{Hutan Kota di Kota Pekanbaru}

Hutan kota berfungsi untuk kelestarian, keserasian dan keseimbangan ekosistem perkotaan yang meliputi unsur lingkungan, sosial dan budaya (Fandeli dkk, 2004). Kota Pekanbaru memiliki 2 hutan kota yaitu hutan kota Kota Pekanbaru dan Taman Pancing hutan kota Alam Mayang.

Hutan kota Kota Pekanbaru terdiri atas berbagai macam jenis tanaman pengisi, antara lain, Bintaro, Mahoni, Kelapa Sawit, Durian, Bambu dan Matoa. Tanaman yang mendominasi di kawasan hutan kota adalah Akasia. Kondisi hutan kota di Pekanbaru tidak terawat dan tampak kotor. Pada hutan kota juga terdapat fasilitas tempat duduk berupa batu dan jogging track.

Taman pancing hutan kota Alam Mayang merupakan tempat yang paling banyak dikunjungi masyarakat Kota Pekanbaru. Pada taman 
ini terdapat berbagai fasilitas rekreasi salah satunya kolam pemancingan. Tanaman pengisi di taman ini adalah Mahoni, Angsana, Trembesi, Kelapa, Akasia, dan Ketapang. Hutan kota Alam Mayang Termasuk ke dalam kategori hutan rekresi, karena dilengkapi sarana bermain, tempat peristirahatan dan kolam pemancingan.

\section{Taman kota}

Kondisi eksisting taman Kota Pekanbaru telah tertata dengan baik. Kombinasi tanaman yang dipilih memunculkan estetika yang menarik. Taman kota di Pekanbaru berupa taman rekreasi aktif dan taman rekreasi pasif dan rekreasi aktif pasif. Kota Pekanbaru memiliki 2 taman kota rekreasi aktif, yaitu taman kota sebelah Arya Duta dan taman Danau Limbungan. Taman kota sebelah Arya Duta memiliki beragam tanaman pengisi, seperti Mahoni, Akasia, Matoa, Melati air, Kamboja, Palm Ekor Tupai, Bogenvil, Soka, Cemara, Teh-tehan, Krokot, Mawar, Ketela Hias, dan Kiara Payung. Taman ini juga dilengkapi fasilitas mushala, gazebo, kolam, fasilitas bermain seperti ayunan dan perosotan. Taman rekreasi Danau Limbungan merupakan tempat rekreasi berupa danau yang digunakan untuk rekreasi menggunakan perahu. Danau didominasi oleh tanaman Akasia dan Kelapa Sawit. Kondisi taman rekreasi Danau Limbungan saat ini kurang terawatt. Kota Pekanbaru tidak hanya memiliki taman rekreasi aktif, tetapi juga memiliki taman rekreasi aktif dan pasif seperti taman Pasar Bawah. Taman ini diisi oleh tanaman Kiara Payung dan Bogenvil. Taman ini juga terdapat fasilitas berupa air mancur dan tempat duduk bagi pengguna taman. Kota Pekanbaru juga memiliki taman pasif seperti taman Tugu Keris, taman belakang gedung DPRD Provinsi Riau, taman Bundaran Pesawat Sudirman, taman Tugu Bambu Runcing, taman segitiga menuju Bandara Sultan Syarif Qasyim dan taman sebelah Mesjid Agung.

Tabel 2. Data dan Identitas Responden

\begin{tabular}{lcc}
\hline \multicolumn{1}{c}{ Identitas } & Jumlah (jiwa) & Persentase (\%) \\
\hline 1. Umur & 5 & \\
a. $1-14$ tahun & 67 & 6.94 \\
b. $15-55$ tahun & 0 & 93.06 \\
c. $>55$ tahun & & \\
2. Pekerjaan & 11 & \\
a. PNS & 13 & 15.28 \\
b. Pedagang & 41 & 18.06 \\
c. Pelajar & 7 & 56.94 \\
d. Lainnya (Ibu Rumah Tangga, Wiraswasta, & & 9.72 \\
$\quad$ Pegawai Swasta) & & \\
\hline
\end{tabular}

Tabel 2 menunjukkan bahwa persentase responden menurut umur 1-14 tahun adalah $6,94 \%$ dan presentase responden yang berumur 14-55 adalah 93,06\%. Berdasarkan jenis pekerjaannya, sebagian besar responden merupakan pelajar, hal ini dapat dilihat dari tabel 1 dengan jumlah 56,94\% pekerjaan responden merupakan pelajar.

Tabel 3 menunjukkan sebagian besar responden sudah mengetahui apa itu RTH, yakni ditunjukkan oleh 88,89\% responden memilih "ya" pada kuisioner. Sebagian besar responden (72,22\%) menyatakan pengertian RTH adalah ruang kosong yang diisi oleh tumbuhan atau tanaman.

Berdasarkan pertanyaan pada Tabel 3 tentang kondisi Kota Pekanbaru, 95,83\% responden menjawab kondisi Kota Pekanbaru panas. Hasil ini menunjukkan adanya kesesuaian dengan publikasi yang dikatakan Media Indonesia.com bahwa kondisi suhu Kota Pekanbaru panas berkisar $34^{\circ} \mathrm{C}-35^{\circ} \mathrm{C}$. Kondisi ini sesuai dengan pernyataan masyarakat tentang jumlah RTH di Kota Pekanbaru dimana sebagian besar responden menyatakan bahwa RTH yang ada masih kurang banyak dan sangat kurang banyak (81,94\%), 
sehingga semua responden menyatakan bahwa Kota Pekanbaru masih membutuhkan penambahan tanaman (Tabel 3). Hal ini menunjukkan bahwa masyarakat Kota Pekanbaru membutuhkan lingkungan yang nyaman.

Tabel 3. Persepsi Masyarakat Pekanbaru Tentang Ruang Terbuka Hijau (RTH)

\begin{tabular}{|c|c|c|}
\hline Pertanyaan & Jumlah & $\%$ \\
\hline \multicolumn{3}{|l|}{ Apakah anda mengetahui apa yang dimaksud dengan RTH } \\
\hline a. Ya & 64 & 88,89 \\
\hline b. Tidak & 8 & 11,11 \\
\hline \multicolumn{3}{|l|}{ Pengertian dari RTH (jawaban boleh lebih dari 1) } \\
\hline a. Ruang kosong yang diisi oleh tumbuhan atau tanaman & 52 & 72,22 \\
\hline b. Kumpulan pepohonan dalam area tertentu & 30 & 41,66 \\
\hline $\begin{array}{l}\text { c. Kumpualan pohon yang menyebar dan atau dalam } \\
\text { gerombolan kecil }\end{array}$ & 14 & 19,44 \\
\hline d. Lainnya...(tidak tahu) & 8 & 11,11 \\
\hline \multicolumn{3}{|l|}{ Bagaimana kondisi kota Pekanbaru } \\
\hline a. Panas & 69 & 95,83 \\
\hline b. Berdebu & 2 & 2,78 \\
\hline c. Sejuk & 0 & 0 \\
\hline d. Nyaman & 1 & 1,39 \\
\hline e. Lainnya.... & 0 & 0 \\
\hline \multicolumn{3}{|l|}{ Bagaimana dengan jumlah RTH di kota Pekanbaru } \\
\hline a. Sangat banyak & 0 & 0 \\
\hline b. Banyak & 13 & 18,06 \\
\hline c. Kurang banyak & 45 & 62,50 \\
\hline d. Sangat kurang banyak & 14 & 19,44 \\
\hline \multicolumn{3}{|l|}{ Kota Pekanbaru membutuhkan tambahan tanaman } \\
\hline a. Ya, membutuhkan & 72 & 100 \\
\hline b. Tidak & 0 & 0 \\
\hline \multicolumn{3}{|l|}{ Manfaat RTH (jawaban boleh lebih dari 1) } \\
\hline a. Mempertahankan kulaitas lingkungan & 58 & 80,55 \\
\hline b. Keindahan lingkungan & 27 & 37,50 \\
\hline c. Sarana rekreasi & 8 & 11,11 \\
\hline d. Lainnya.. & 0 & 0 \\
\hline \multicolumn{3}{|l|}{ Dalam bentuk apakah RTH diinginkan (jawaban boleh lebih dari 1) } \\
\hline a. Hutan Kota & 41 & 56,94 \\
\hline b. Taman Kota & 49 & 65,05 \\
\hline c. Tanaman Tepi Jalan & 33 & 45,83 \\
\hline d. Lainnya & 0 & 0 \\
\hline
\end{tabular}

Berdasarkan pertanyaan tentang penambahan tanaman di kota Pekanbaru pada tabel 2, semua responden menjawab membutuhkan. Pengetahuan responden tentang manfaat RTH
(Tabel 3) menyatakan manfaat RTH adalah untuk mempertahankan lingkungan (80,55\%). Penyataan masyarakat tentang bentuk RTH yang diinginkan di Kota Pekanbaru sangat beragam, yaitu 56,94\% menyatakan dalam bentuk hutan kota, 65,05\% menyatakan dalam bentuk taman kota, dan 45,83\% menyatakan dalam bentuk tanaman tepi jalan. Banyaknya responden yang menginginkan RTH dalam bentuk taman kota dan hutan kota, terkait dengan terbatasnya area terbuka yang diakses oleh masyarakat untuk kepentingan rekreasi warga.

Tabel 4. Persepsi Masyarakat Pekanbaru Tentang Tanaman Asli kota Pekanbaru

\begin{tabular}{lcc}
\hline \multicolumn{1}{c}{ Pertanyaan } & Jumlah & $\%$ \\
\hline Tahukah anda tanaman asli Pekanbaru & & \\
a. Ya,.... & 4 & 5,56 \\
b. Tidak & 68 & 94,44 \\
Perlukah memunculkan tanaman asli Pekanbaru & 30 & 41,67 \\
a. Sangat perlu & 36 & 50 \\
b. Perlu & 6 & 8,33 \\
c. Tidak perlu & & \\
d. Sangat tidak perlu & & \\
Kemungkinannya dikembangkan di kota Pekanbaru & 64 & 88,89 \\
a. Ya, sangat mungkin & 8 & 11,11 \\
b. Tidak mungkin & & \\
\hline
\end{tabular}

Berdasarkan Tabel 4, pernyataaan responden mengenai pengetahuan tentang tanaman asli Pekanbaru sebagian besar menyatakan tidak tahu (94,44\%). Namun 5,56\% menyatakan tahun tanaman asli Pekanbaru yaitu Akasia dan Manggis. Ketidaktahuan masyarakat terhadap tanaman asli daerah menunjukkan bahwa informasi mengenai tanaman asli Pekanbaru tidak disampaikan secara baik, akibatnya akan menghilangkan pengetahuan tentang tanaman asli daerah yang berakibat terhadap musnahnya tanaman tersebut. Oleh karena itu perlu sosialisasi mengenai tanaman asli daerah kepada masyarakat terhadap generasi muda, sehingga dapat menjaga kelestari- 
an tanaman tersebut. Sebagian besar responden menyatakan sangat perlu dan perlu $(91,67 \%)$ dimunculkannya tanaman khas Pekanbaru. Pernyataan responden tentang kemungkinannya tanaman khas Pekanbaru dikembangkan di Kota Pekanbaru sebagian besar menyatakan sangat mungkin $(88,89 \%)$.

Tabel 5. Persepsi Masyarakat Pekanbaru Tentang Taman Kota dan Hutan Kota

\begin{tabular}{lcc}
\hline \multicolumn{1}{c}{ Pertanyaan } & Jumlah & $\%$ \\
\hline Apakah kota Pekanbaru membutuhkan taman kota & & \\
a. Sangat Membutuhkan & 48 & 66,67 \\
b. Membutuhkan & 24 & 33,33 \\
c. Tidak membutuhkan & 0 & 0 \\
d. Sangat tidak Membutuhkan & 0 & 0 \\
Jenis taman kota yang diinginkan & & \\
a. Taman bermain & 7 & 9,72 \\
b. Taman rekreasi & 35 & 48,61 \\
c. Taman dengan bermacam-macam tanaman hias & 30 & 41,67 \\
d. Lainnya & 0 & 0 \\
Bagaimana kondisi penataan taman kota di Kota Pekanbaru & & \\
a. Sangat bagus & 14 & 19,44 \\
b. Bagus & 17 & 23,62 \\
c. Cukup Bagus & 35 & 48,61 \\
d. Kurang bagus & 6 & 8,33 \\
Pentingnya keberadaan hutan kota di Kota Pekanbaru & & 97,22 \\
a. Penting & 2 & 2,73 \\
b. Tidak penting & & \\
\hline
\end{tabular}

Berdasarkan Tabel 5, pernyataan responden tentang kota Pekanbaru membutuhkan taman kota sebagian besar menyatakan sangat membutuhkan/membutuhkan, hal itu ditunjukkan oleh 100\% responden menyatakan sangat membutuhkan/membutuhkan. Responden menyatakan jenis taman kota yang diinginkan berupa taman rekreasi $(48,61 \%)$ dan taman dengan bermacammacam tanaman hias (41,67\%). Sebagian besar responden menyatakan kondisi penataan taman kota di Kota Pekanbaru cukup bagus (48,61\%). Namun masyarakat Pekanbaru juga menyatakan kondisi taman kota di Kota Pekanbaru sangat ba- gus/bagus (42,06\%). Masyarakat Kota Pekanbaru menyatakan bahwa keberadaan hutan kota penting. Hal ini ditunjukkan oleh $97,22 \%$ responden menyatakan penting.

Sedangkan pada Tabel 6, pernyataan responden tentang kondisi jalan di kota Pekanbaru sebagian besar menyatakan panas $(52,78 \%)$ dan berdebu (40,28\%). Pernyataan responden tentang jumlah pohon peneduh di pinggir jalan Kota Pekanbaru sebagian besar menyatakan kurang banyak dan sangat kurang banyak (59,71\%). Sebagian besar responden menyatakan fungsi tanaman tepi jalan adalah sebagai penyerap polusi udara (72,22\%). Responden menyatakan sangat setuju dan setuju (100\%) dilakukannya penambahan tanaman tepi jalan di Kota Pekanabaru, hal ini agar pengguna jalan merasa nyaman apabila melewati jalan-jalan yang ada di Kota Pekanbaru.

Tabel 6. Persepsi Masyarakat Pekanbaru Tentang Jalur Hijau Jalan

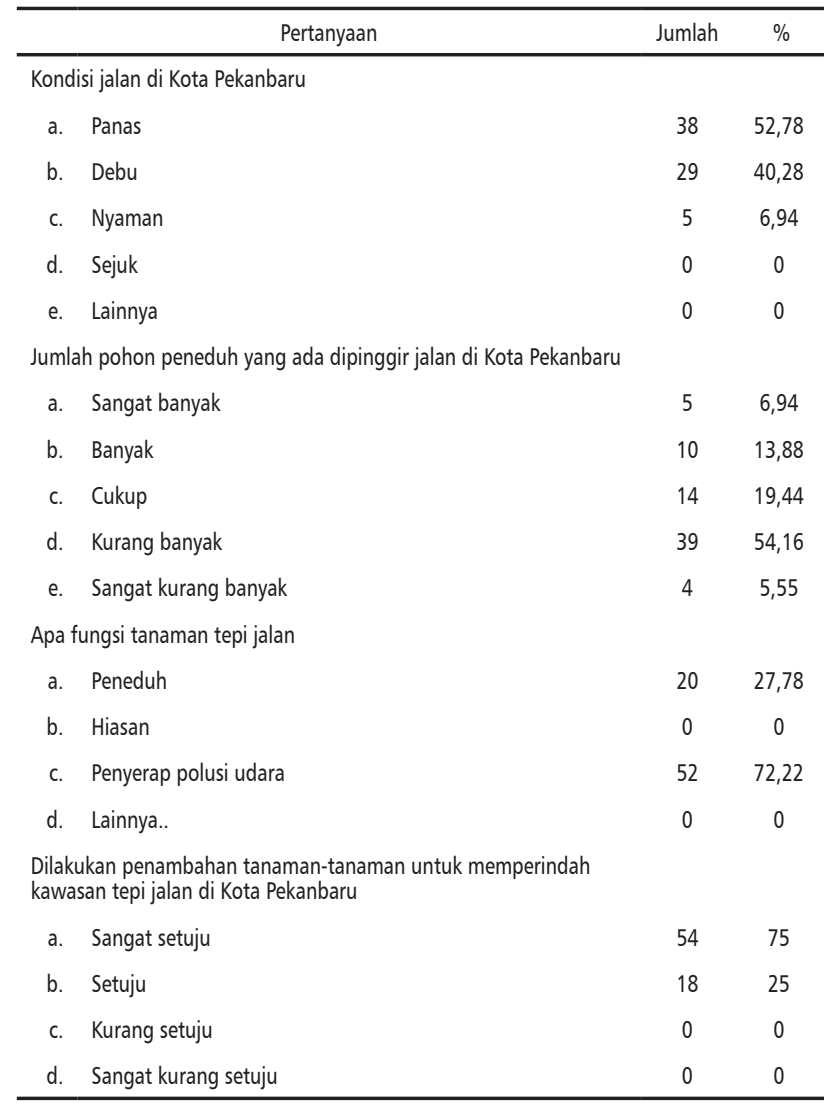


Rencana Tata Ruang Wilayah (RTRW) Kota Pekanbaru

Dalam Rencana Penggunaan Lahan Kota Pekanbaru Tahun 2007-2016, jenis penggunaan lahan terbagi menjadi 2 yaitu kawasan budidaya/ kawasan terbangun $(31.515,28 \mathrm{Ha})$, lain-lain (684 Ha), dan kawasan lindung/RTH (31.025,92 $\mathrm{Ha}$ ) atau 49,07\% dari luas seluruh wilayah Kota Pekanbaru.

Dari segi kepemilikan RTH dapat berupa RTH publik yang dimiliki oleh umum dan terbuka bagi masyarakat luas, atau RTH privat (pribadi) yang berupa taman-taman yang berada pada lahan-lahan pribadi (Undip 2010). Berdasarkan UU Nomor 26 tahun 2007, minimal jumlah RTH di suatu wilayah adalah 30\% dari luas wilayah tersebut, yang terdiri dari 20\% RTH publik dan 10\% RTH privat. Berdasarkan total persentase kawasan terbangun $(24,19 \%)$ dan non terbangun $(75,81 \%)$ di Kota Pekanbaru, RTH publik terdapat dalam kawasan non terbangun pada kawasan lindung, kawasan danau wisata dan kuburan dengan total persentase seluas 4,35\%. Evaluasi RTH di Kota Pekanbaru dilakukan pada jenis RTH publik karena RTH publik memiliki kekuatan hukum sehingga sulit nantinya untuk beralih fungsi menjadi kawasan yang peruntukannya bukan untuk RTH. Jika dilihat dari persentase luas RTH publik di Kota Pekanbaru, ketersediaan RTH publik di Kota Pekanbaru masih kurang dari jumlah yang telah ditetapkan dalam UU Nomor 26 tahun 2007 (minimal 20\% dari luas wilayah), yaitu sebesar 15, 65\%. Menurut rencana penggunaan lahan Kota Pekanbaru tahun 2007-2016 dalam RTRW Kota Pekanbaru RTH publik khususnya kawasan lindung direncanakan seluas 49,07\%. Kawasan lindung digunakan untuk pengadaan hutan lindung, resapan air, sempadan sungai, buffer zone, hutan kota, RTH kota, dan kawasan cagar budaya.
Tabel 7. Pemanfaatan lahan di Kota Pekanbaru

\begin{tabular}{llcc}
\hline No. & Jenis Penggunaan & Luas $(\mathrm{Ha})$ & $(\%)$ \\
\hline 1. & Perumahan & $10.914,44$ & 17,26 \\
2. & Perdagangan & 1428 & 2,26 \\
3. & Pemerintahan & 100,23 & 0,15 \\
4. & Perguruan Tinggi & 282,30 & 0,45 \\
5. & Militer & 134,93 & 0,21 \\
6. & Industri \& Cevron & $1.794,94$ & 2,83 \\
7. & Utilitas dan Fasilitas Umum & 616,22 & 0,98 \\
8. & Kawasan Budaya & 36,62 & 0,05 \\
Kawasan Terbangun & $15.307,68$ & 24,19 \\
1. & Kuburan & 68,92 & 0,11 \\
2. & Danau Wisata & 183,71 & 0,30 \\
3. & Kawasan lindung & $2.487,65$ & 3,94 \\
4. & Lain-lainya & $45.178,04$ & 71,46 \\
Kawasan Non Terbangun & $47.918,32$ & 75,81 \\
Jumlah Total & 63.226 & 100,00 \\
\hline
\end{tabular}

\section{Perencanaan RTH di Kota Pekanbaru}

RTH merupakan ruang berfungsi sebagai pengaman pencemaran, sarana rekreasi, pengendali iklim hidup mikro, sarana menciptakan kesehatan dan kehidupan lingkungan. Keberadaan RTH sangat dibutuhkan masyarakat Pekanbaru khususnya mengingat suhu udara di Kota Pekanbaru yang panas agar terciptanya suasana nyaman di Kota Pekanbaru.

\section{Perencanaan Jalur Hijau Jalan di Kota Pekanbaru}

Model perencanaan jalur hijau jalan di Jl.

Sukarno Hatta didasarkan pada kebutuhan jalan akan tanaman peneduh, penahan angin dan penyerap polusi (Dirjen Tata Ruang, 2012). Tanaman Sukarno Hatta juga sering dilalui kendaraan roda 4 - roda 8 seperti truk dan bus. Jalur ini merupakan jalur menuju terminal Payung Sekaki dan menuju Kabupaten Kampar. Pemilihan tanaman Akasia Daun Besar selain berfungsi sebagai peneduh juga sebagai penahan laju angin, kemudian penambahan tanaman Kembang Sepatu juga sebagai filter penahan laju angin dan memberikan kesan lebih beragam karena tanaman Kembang Sepatu merupakan tanaman 
bunga yang memiliki nilai estetika. Pemilihan Bogenvil dan Pangkas Kuning pada median jalan berfungsi sebagai penyerap polusi udara. Kemudian tanaman pelantai berupa rumput Gajah Mini memberi paduan warna yang eksotis dari perpaduan bogenvil merah dan bogenvil putih. Pada pohon Akasia diberi piringan yaitu ruang kosong tanpa perkerasan yang berfungsi sebagai tempat pemberian nutrisi pada pohon. Kemudian pemberian perkerasan jalan berupa paving block akan memberikan kesan bersih dan dapat digunakan untuk jalur pejalan kaki.

Kondisi Jl. Subrantas dan Jl. Tuanku Tambusai memiliki kemiripan. Keberadaan tanaman tepi jalan di ruas jalan tersebut belum mampu menahan kencangnya angin yang ada dan menurunkan suhu yang terasa sangat panas. Model perencanaan jalur hijau jalan Jl. Subrantas dan Jl. Tuanku Tambusai disesuaikan dengan kondisi Jl. Subrantas dan Jl. Tuanku Tambusai. Panasnya suhu udara di jalan ini cocok diberikan tanaman peneduh dan penyerap polusi udara seperti angsana. Kaca Piring sebagai tanaman perdu ditanam di pinggir jalan sebagai penahan angin. Pembuatan piringan pada tanaman peneduh sebagai tempat untuk memberikan nutrisi/pupuk agar menjaga perakaran tidak keluar merusak perkerasan di pinggir jalan. Pada sempadan bangunan diberi paving block yang berlubang agar bisa ditanami tanaman pelantai seperti rumput gajah mini. Median jalan ditanami tanaman pengarah berupa Cemara dan tanaman pelantai rumput Gajah Mini. Untuk menambah estetika pada tepi jalan diberi pot yang berisi tanaman Agave dan Krokot (Dirjen Tata Ruang, 2012).

Kondisi Jl. Riau , Jl. Hang Tuah dan Imam Munandar memiliki persamaan, yaitu kondisi jalan yang panas dan dipenuhi perkerasan. Perencanaan Tanaman tepi jalan pada Jl. Riau, Jl. Hang Tuah, dan Jl. Imam Munandar didas- arkan pada kebutuhan jalan terhadap tanaman peneduh. Pemilihan tanaman pada perencanaan jalan ini menggunakan tanaman peneduh Kiara Payung. Penambahan pergola pada pinggir jalan menambah keteduhan jalan dan berfungsi untuk pengguna pejalan kaki. Pinggir jalan pada pergola diberi Pangkas Kuning sebagai pembatas dan sebagai tanaman penyerap polusi udara serta menambah estetika (Dirjen Tata Ruang, 2012).

\section{Perencanaan Hutan Kota di Kota Pekanbaru}

Model perencanaan hutan kota yang direncanakan adalah hutan kota rekreasi dengan penggabungan elemen lunak dan elemen keras. Elemen lunak adalah elemen yang tersusun oleh tanaman dan elemen keras adalah elemen yang tersusun oleh perkerasan/yang bukan tanaman. Elemen lunak yang digunakan adalah tanaman pohon (Mahoni, Akasia, Kiara Payung, Dadap Merah, Tanjung, Kelapa Kopyor, Kelapa Sawit, Sengon, Matoa ) dan perdu (Pangkas Kuning dan Kembang Sepatu). Tanaman Akasia ditempatkan pada sekeliling batas tepi hutan kota. Perencanaan ini dilakukan untuk memunculkan tanaman asli Pekanbaru (berdasarkan pendapat responden). Hutan kota juga diberi tanaman pelantai (rumput Gajah Mini) dan tanaman penutup tanah (Krokot). Kiara Payung dan Dadap Merah berfungsi sebagai pohon pengundang burung. Kiara Payung dapat mengundang burung Punai dan Dadap Merah dapat mengundang burung Betet, Srindit, Jalak dan beberapa jenis burung madu (Dirjen Tata Ruang, 2012). Pemilihan elemen keras berupa air mancur dan ornamen tiang batu berbentuk bulat berfungsi sebagai focal point dalam perencanaan. Kolam pemancingan dan taman-taman mini berguna sebagai sarana rekreasi bagi masyarakat Kota Pekanbaru. Pada area hutan kota dibangun kios-kios untuk berjualan yang terletak di beberapa titik. 
Model hutan rekreasi dipilih bukan hanya untuk rekreasi bagi masyarakat setempat namun juga dapat menambah pemasukan daerah. Sebagian dari pemasukan dari hutan kota Kota Pekanbaru dapat digunakan untuk perawatan hutan kota, dengan ini hutan kota akan terjaga kualitas hutannya maupun keindahannya. Lampu-lampu dalam perencanaan berfungsi untuk menjaga suasana hutan kota tetap hidup di malam hari. Kemudian di sekeliling kolam pemancingan ditaman Matoa dan diberi bangku-bangku untuk pengguna pada kolam pemancingan.

\section{Perencanaan Taman Kota di Kota Pekanbaru}

Persepsi masyarakat Kota Pekanbaru terhadap taman kota di Kota Pekanbaru cukup baik. Masyarakat sebagian besar menyatakan menginginkan taman kota dengan berbagai tanaman hias dan taman rekreasi. Persimpangan Jl. Subrantas merupakan ruas jalan yang lebar namun belum terdapat RTH di persimpangan tersebut. perencanaan taman persimpangan Jl. Subrantas didasarkan pada kebutuhan tanaman peneduh dan ruang untuk interaksi yakni sebuah taman mini pada ujung persimpangan. Tanaman peneduh berupa Angsana ditanam di pinggir dan median jalan agar jalan teduh dan nyaman. Pada pinggir jalan bagian selatan diberi pot berisi tanaman melati air untuk menambah estetika dan mengurangi suasana gersang. Pinggir jalan bagian selatan juga diberi pergola sebagai peneduh. Taman mini dibuat di sisi sebelah kanan dan kiri untuk tempat peristirahatan bagi pengguna pasar. Taman berisi Gazebo dan tempat duduk. Tanaman pengisinya yaitu Angsana, Palm Putri, Bogenvil, Pangkas Kuning dan Teh-tehan. Tanaman pelantainya adalah rumput Gajah Mini. Untuk menambah nilai estetika diberi pot bunga berisi bunga Melati Air. Bagian barat jalan, pinggir jalan ditanam Palm Raja sebagai tanaman peneduh. Pemilihan tanaman dibuat berbeda untuk mendapatkan suasana yang berbeda-beda tiap ruas jalan. Pulau Jalan bagian selatan yang dulu hanya diberi rumput gajah dan lampu diberi Palm Putri sebagai penambah nilai estetika. Pada pinggiran Pulau Jalan ditanam Teh-tehan yang berfungsi sebagai pembatas. Penambahan lampu pada Pulau Jalan bertujuan untuk tetap memberi kesan hidup pada pulau jalan saat malam hari.

\section{SIMPULAN}

Dari penelitian ini dapat disimpulkan bahwa Kota Pekanbaru memiliki 4,35\% RTH publik dalam bentuk kawasan lindung (jalur hijau, taman kota, hutan kota), kuburan dan danau wisata sehingga Kota Pekanbaru belum memiliki luas RTH publik sesuai UU Nomor 26 tahun 2007 minimal 20\% dari luas wilayah dan RTRW Kota Pekanbaru minimal 49\% dari luas wilayah. Model perencanaan jalur hijau jalan di Jl. Sukarno Hatta, Jl. Riau, Jl. Hang Tuah, Jl. Imam Munandar Jl. Subrantas, dan Jl. Tuanku Tambusai didasarkan pada kebutuhan jalan pada tanaman peneduh, penahan angin dan penyerap polusi. Model perencanaan hutan kota yang direncanakan adalah hutan kota rekreasi dengan penggabungan tanaman dan perkerasan. Model perencanaan taman persimpangan Jl. Subrantas didasarkan pada kebutuhan tanaman peneduh dan ruang untuk interaksi para pengguna pasar.

Ketersediaan RTH di Kota Pekanbaru harus benar-benar dijaga sebaik mungkin, baik itu dari pemerintah setempat (BAPPEDA, Dinas Pertamanan, Dinas Pertanian) maupun masyarakat Kota Pekanbaru. Pembuatan peraturan pemerintah setempat dengan sanksi yang tegas tentang alih fungsi lahan peruntukan RTH dapat menjadi tameng yang kuat untuk mempertahankan RTH di Kota Pekanbaru. 


\section{DAFTAR PUSTAKA}

Dirjen Tata Ruang, 2012. Rencana Detail Tata Ruang Wilayah Kota. http://www.penataanruang.com/rdtr-kota.html. Diakses pada April 2012

Media Indonesia. 2010. Suhu Di Pekanbaru Capai 35 Derajad Celcius Dalam http://www.mediaindonesia.com/ read/2010/04/04/135938/126/101/Suhu-di-PekanbaruCapai-35-Derajat-Celcius diakses tanggal 20 April 2010.

Nugroho, F. A. 2006. Ruang Terbuka Hijau Di Citraya Surabaya Sebagai Bagian Dari Lanskap Kota Surabaya Dalam Mewujudkan Kota Yang Hijau. Ciputra Raya. Prosiding Seminar Lanskap Perkotaan-Green City "Strategi dan Implementasi Penataan Ruang Terbuka Hijau (RTH) dan Lanskap Perkotaan dalam Mewujudkan Green-City . 31.

Peraturan Menteri Pekerjaan Umum. 2010. Tentang Pedoman Penyediaan dan Pemanfaatan Ruang Terbuka Hijau. Dalam Peraturan Menteri Pekerjaan Umum : 05/PRT/M/2008 tentang pedoman penyediaan dan pemanfaatan ruang terbuka hijau-www.jkpp.org/downloads/Permen\%2005-2008.pdf diakses tanggal 25 November 2010.

Undang-Undang Republik Indonesia Nomor 26 tahun 2007 Tentang Penataan Ruang. Dalam http://www.penataan ruang. net/taro/nspm/UU No 262007 Tentang Penataan Ruang.pdf diakses tanggal 5 Desember 2009. 